\title{
Metabolic Syndrome and Incident Asthma in Chinese Adults: An Open Cohort Study
}

This article was published in the following Dove Press journal:

Diabetes, Metabolic Syndrome and Obesity: Targets and Therapy

\author{
Haixia Wang \\ Chenxiao Bai \\ Mo Yi \\ Yuanmin Jia \\ Yizhang Li \\ Di Jiang \\ Ou Chen
}

School of Nursing, Cheeloo College of Medicine, Shandong University, Jinan 2500 I2, Shandong, People's Republic of China
Correspondence: Ou Chen School of Nursing, Cheeloo College of Medicine, Shandong University, Jinan 250012, Shandong, People's Republic of China

$\mathrm{Tel}+8615990991181$

Email chenou@sdu.edu.cn
Background: Although metabolic syndrome is awell-known risk factor for many noncommunicable diseases, its contribution to asthma remains controversial.

Objective: The aim of this study was to explore the associations of metabolic syndrome and its components with incident asthma in Chinese adults.

Methods: We conducted an open cohort study of participants who were asthma-free at baseline $(n=42,304)$ in the Shandong multi-center health check-up longitudinal study from 2004 to 2015 . Participants aged $\geq 20$ years and had regular physical examination (once ayear) more than three times during follow-up.

Results: Ninety subjects (38 women and 52 men) developed incident asthma over 12 years of follow-up. Our study suggested that metabolic syndrome itself was not significantly associated with incident asthma in either women or men $(P>0.050)$. Interestingly, we found that overweight and/or obesity was arisk factor for incident asthma among women but not men in the Cox proportional hazards model after adjusting covariates (adjusted incidence rate ratio $(I R R)=2.940,95 \%$ confidence interval $(\mathrm{CI})$ : $1.467-5.894, \mathrm{P}=0.002)$. The result was consistent with the Poisson regression model (hazard ratio $(\mathrm{HR})=2.241,95 \%$ CI: $1.135-4.988, \mathrm{P}=0.026$ ). After stratifying according to overweight and/or obesity, we found that female subjects with overweight and obesity were associated with the occurrence of incident asthma $(P<0.050)$. However, we did not find this result among men.

Conclusion: Metabolic syndrome was not significantly associated with incident asthma in both women and men; however, overweight and/or obesity was shown to be asignificant risk factor for incident asthma but only in women, not in men.

Keywords: overweight and/or obesity, metabolic syndrome, risk factor, incident asthma

\section{Introduction}

Asthma is achronic inflammatory disease caused by gene-environment interactions, with symptoms of wheezing, coughing, chest tightness, and shortness of breath. ${ }^{1}$ Prevalence rates for asthma have been increasing in many countries over the past few decades. ${ }^{2-4}$ Approximately 235 million people worldwide suffer from asthma. ${ }^{5}$ Asthma has become one of the most common diseases in the world, resulting in asubstantial disease burden. ${ }^{6}$ Therefore, it is particularly important to prevent asthma by identifying risk factors for asthma, such as smoking, allergic rhinitis, eczema, psychosocial factors, rhinitis, sinusitis, lung infections, alcohol consumption, air pollution and occupational exposure. ${ }^{7-10}$

Overweight and/or obesity is avast public health problem and amajor risk factor for asthma in adults. ${ }^{11,12}$ Overweight and/or obesity is considered part of the metabolic syndrome in China. ${ }^{13}$ Metabolic syndrome is awell-known cluster of 
cardiometabolic risk factors associated with an increased risk of multiple chronic diseases, including cancer and cardiovascular disease, and is associated with an approximately 2-fold higher risk of cardiovascular disease and a5fold or more increase in the risk of type 2 diabetes mellitus. ${ }^{14-16}$ In addition, metabolic syndrome is associated with lung function impairment. ${ }^{17-19}$

More recently, literature has emerged that offers contradictory findings of the epidemiological link between metabolic syndrome and asthma. ${ }^{20-23}$ Prior studies that have noted that metabolic syndrome and its components (high waist circumference (WC), lower high-density lipoprotein cholesterol (HDL-C) and elevated glucose, insulin resistance (IR) or diabetes) were associated with an increased risk of asthma. ${ }^{22,23}$ However, some evidence suggested that metabolic syndrome predicted incident asthma among women but not men. ${ }^{20}$ In addition, surveys such as that conducted by Tomita etal ${ }^{21}$ have shown that metabolic syndrome was not arisk factor for the incidence of late-onset asthma. However, whether metabolic syndrome was arisk factor for asthma was not known in the Chinese population. Based on this, our study aimed to explore the relationship between metabolic syndrome and its components and incident asthma in Chinese adults.

\section{Methods}

\section{Study Design}

This was an open cohort study that the original participants exited continuously and new objects joined at any time, covering more than 20 health management centres in Shandong Province from January2004 to December2015. The longitudinal observational study included 76,368 participants who were free from asthma at baseline, covering nearly all of Shandong Province. ${ }^{24}$ The study design and age distribution of this population are shown in Figures 1 and 2. The study was approved by the Institutional Ethical Committee, School of Nursing, Cheeloo College of Medicine, Shandong University (2003-R-036). The study was in compliance with the Declaration of Helsinki for clinical research. All participants provided written informed consent before participating in the study.

The research data were obtained through questionnaire surveys, healthy physical measurements and laboratory examinations of the participants. The questionnaire survey included age, gender, disease history, drinking status and smoking status. Physical measurement indicators included height, weight, systolic blood pressure (SBP) and diastolic blood pressure (DBP). Laboratory indicators included



Figure I Age distribution of the population. 


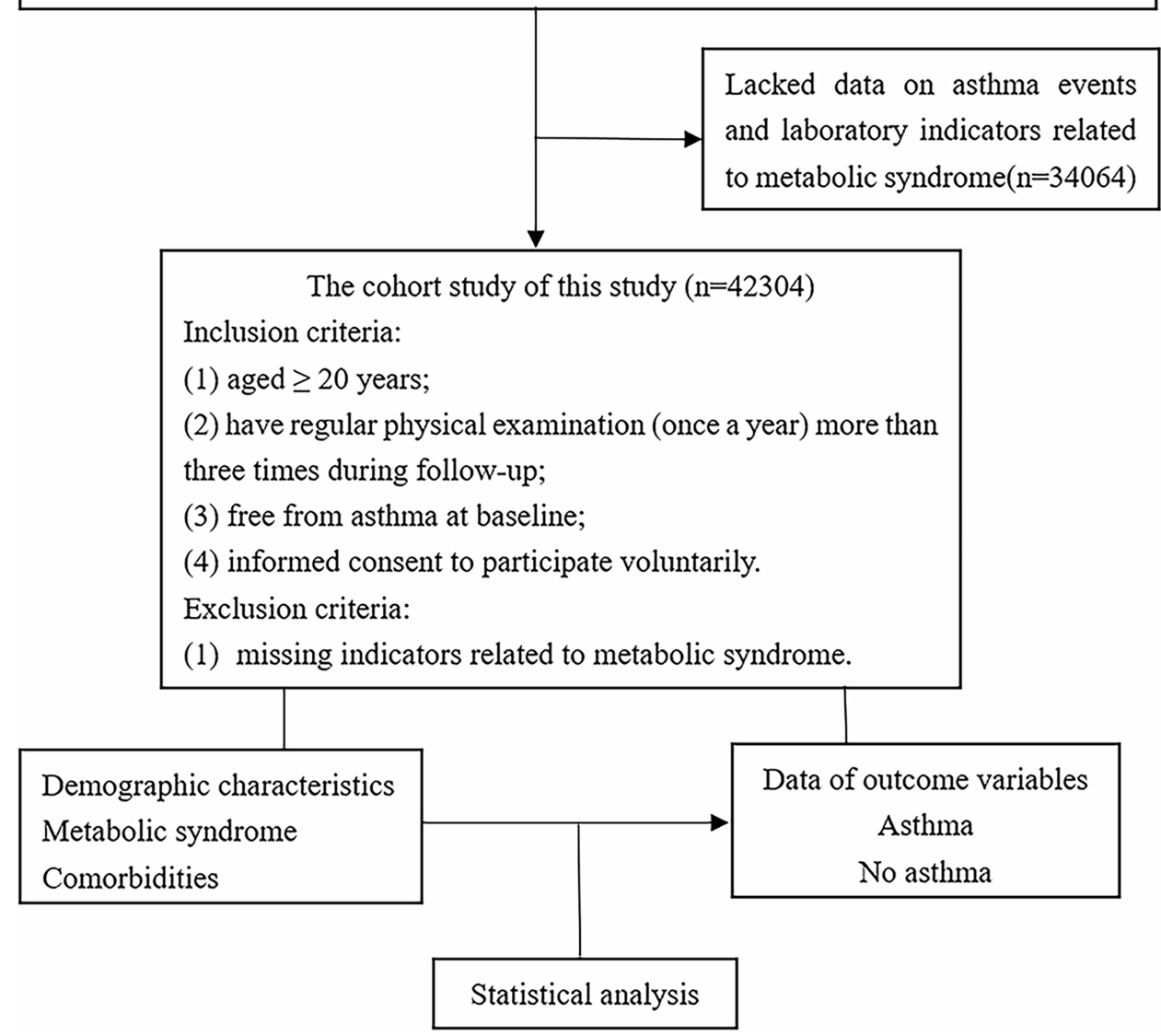

Figure 2 Study design.

fasting plasma glucose (FPG), triglycerides (TGs), and HDL-C, etc. Height and weight were measured with light clothing without shoes; BP was measured using Omron HEM-907 by the cuff-oscillometric method on the right arm in sitting position after a5-min rest, and the mean SBP and DBP values of two measurements were recorded, respectively. In addition, participants needed fasting for more than $12 \mathrm{~h}$.

In the follow-up, we collected asthma-related diseases (rhinitis, nasal polyps, pneumonia, bronchiectasis, pulmonary infection, bronchitis, and Chronic obstructive pulmonary disease (COPD)), these diseases were selfreported by participants, including nasal polyps. The doctor at the medical center also confirmed the diagnosis based on the patient's symptoms and related laboratory tests, because nasal polyps coexist with sinusitis. ${ }^{25}$ In this study, nasal polyps were only nasal polyps without accompanying sinusitis.

\section{Inclusion and Exclusion Criteria}

The inclusion criteria were as follows: 1) participants aged $\geq 20$ years; 2) participants had regular physical examination (once ayear) more than three times during follow-up; 3) participants in the study who did not have asthma at baseline diagnosed by doctors at the Health Management Center; and 4) individuals who provided informed consent to participate voluntarily. The exclusion criteria were as follows: missing indicators related to metabolic syndrome at baseline (height, weight, SBP, DBP, FPG, TGs, and HDL-C). Finally, this study included 42,304 subjects. The median follow-up time was 3.1 years.

\section{Dependent and Independent Variables}

The primary dependent variable was physician-diagnosed asthma during the annual physical examination. The diagnostic criteria for asthma were according to the guidelines 
for Asthma Section, Respiratory Disease Branch, Chinese Medical Association ${ }^{26}$ (Supplementary).

The primary independent variable was metabolic syndrome, including four components. The diagnosis of metabolic syndrome was made using the criteria recommended by the Chinese Medical Association Diabetes Division (CDS) in 2004: $:^{27}$ 1) overweight and/or obesity: BMI $\geq 25.0 \mathrm{~kg} / \mathrm{m}^{2} ; 2$ ) hyperglycaemia: $\mathrm{FPG} \geq 6.1 \mathrm{mmol} / \mathrm{L}$ (110mg/dL), $2 \mathrm{hPG} \geq 7.8 \mathrm{mmol} / \mathrm{L}$ (140mg/dL), and/or diagnosis of and treatment for diabetes; 3 ) hypertension: SBP/ DBP $\geq 140 / 90 \mathrm{mmHg}$ and/or confirmation and treatment of hypertension; 4) TGs $\geq 1.7 \mathrm{mmol} / \mathrm{L}(150 \mathrm{mg} / \mathrm{dL})$ and/or HDL-C $<0.9 \mathrm{mmol} / \mathrm{L}(35 \mathrm{mg} / \mathrm{dL}$ ) (male) or $<1.0 \mathrm{mmol} / \mathrm{L}$ $(39 \mathrm{mg} / \mathrm{dL})$ (female). Metabolic syndrome was diagnosed when 3 or more of the above 4 components met the criteria.

\section{Statistical Analysis}

Considering that studies have shown that the relationship between metabolic syndrome and asthma is different between men and women, we divided the participants into two groups of men and women for analysis. ${ }^{20}$ Acomparison of baseline characteristics (age, sex, BMI, smoking status, drinking status and some respiratory diseases) between participants included and excluded from this cohort study was performed by the chi-square test for categorical variables and the Wilcoxon rank sum test for continuous variables. Multiple analyses were performed using the Cox proportional hazards model to determine the association between metabolic syndrome and its components and incident asthma. Considering the low incidence of asthma in this study, we also performed Poisson regression model to verify the reliability of the results. We included metabolic syndrome and the components of metabolic syndrome in model 1 and model 2, respectively, and adjusted the three covariates of age, drinking and smoking status. Then, statistically significant variables such as overweight and/or obesity and other statistically significant variables in univariate analysis were simultaneously entered into the statistical models to compare the impact of those factors on the outcome; Considering that significant lung diseases might affect our findings, we further excluded participants who diagnosed COPD at follow-up $(n=184)$. The excluded data were also included in the two models for analysis. In addition, we also included participants with BMI data but not included in this study into the Poisson regression and Cox proportional hazards model for statistical analysis. We further included stratification of overweight and obesity into the model for analysis. The statistical significance threshold of IRRs and 95\% CIs was $\mathrm{P}<0.05$. All analyses were performed using IBM SPSS Statistics 24.

\section{Results}

\section{Identification and Characteristics of the Participants}

Among the 76,368 original participants at the baseline examination in the open cohort, 42,304 eligible subjects were included in the study (Figure 3). Ninety eligible subjects developed incident asthma during the follow-up, including 38 women (42.22\%) and 52 men (57.78\%). Compared to the excluded participants, included participants exhibited different demographic characteristics, generally lower age, more women, less smoking, less drinking and less asthma-like respiratory diseases (Supplementary Table 1).

\section{Characteristics of the Participants}

As shown in Table 1, we found that older individuals, drinker (people who are drinking or used to drink), smokers (people who are smoking or have smoked), people with higher DBP or those who had respiratory diseases (nasal polyps, pneumonia, bronchitis, COPD, bronchiectasis) were more likely to develop incident asthma among men. In addition, the results showed that people who were older, had higher TGs, were overweight and/or obese, and had incident respiratory diseases (pneumonia, bronchitis, COPD, bronchiectasis) were more likely to develop incident asthma among women.

\section{Relationship Between Metabolic Syndrome and Its Components and Incident Asthma}

The associations of metabolic syndrome and its components with incident asthma are shown in Table 2. Metabolic syndrome could not predict incident asthma in men and women after adjusting for age, drinking and smoking status $(P>0.05)$ in model 1 . Of the four metabolic syndrome components, only the associations for overweight or/and obesity remained relatively stable after adjustment for all covariates among women $(P<0.05)$ in model 2. However, this result was not found among men. We also used the Poisson regression model for analysis, and the analysis results were similar in the Cox proportional hazard model analysis (Supplementary Table 2). The 


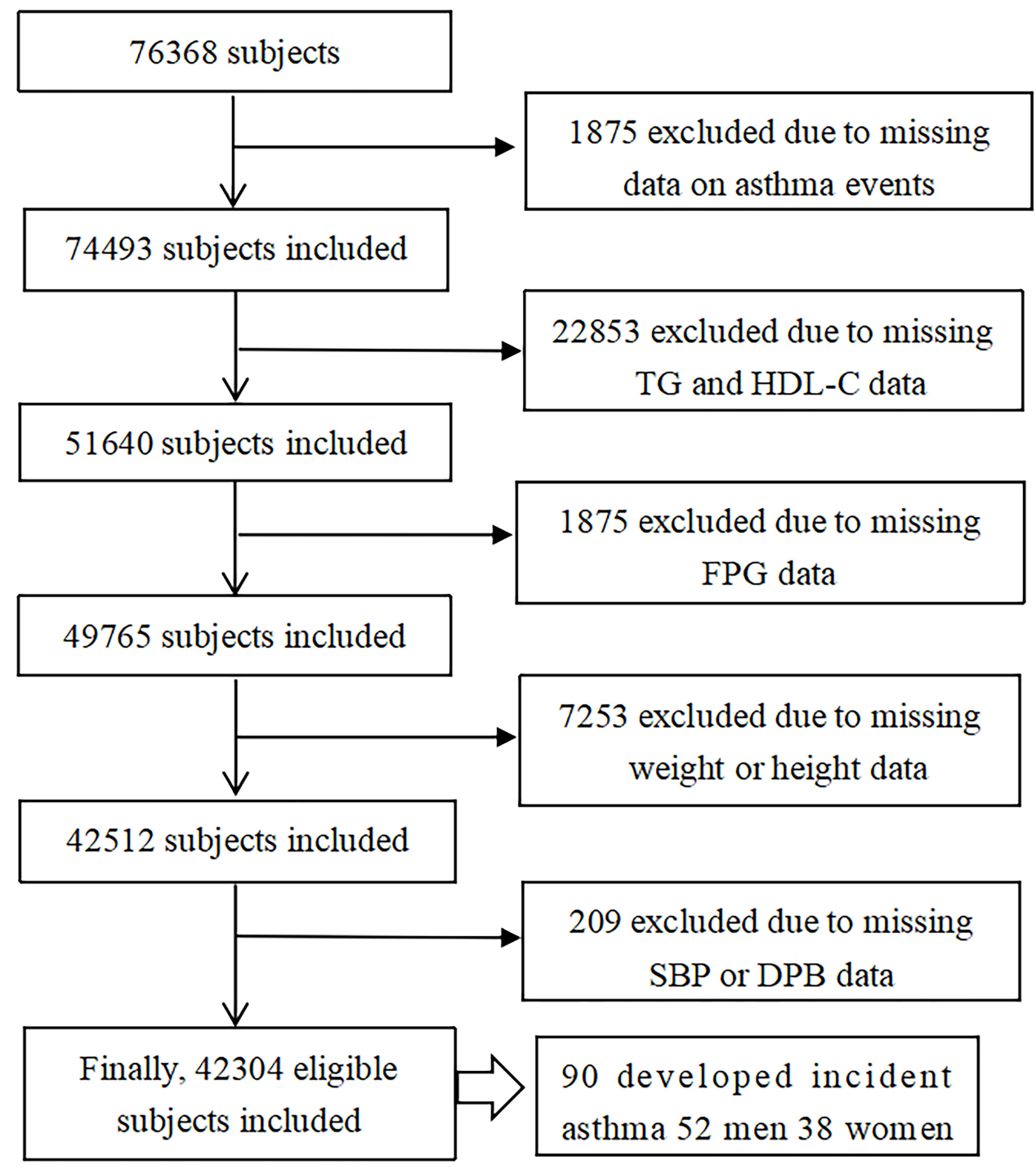

Figure 3 Overview of study participant.

Abbreviations: SBP, systolic blood pressure; DBP, diastolic blood pressure; FPG, fasting plasma glucose; TG, triglyceride; HDL-C, high-density lipoprotein cholesterol.

relationship between overweight and/or obesity and incident asthma was statistically significant after adjusting for and unadjusted covariates (age, smoking and drinking status) (Table 3, Supplementary Table 3).

After stratifying by overweight and obesity, we found that overweight and obesity were associated with the occurrence of incident asthma among women $(\mathrm{P}<0.05)$. However, we did not find this result among men (Table 4). We used the Poisson regression model for analysis, and the analysis results were similar in the Cox proportional hazard model analysis (Supplementary Table 4). The Characteristics of participants with BMI data but excluded in the study in supplementary Table 5. We also verified this result in excluded population including women (Supplementary

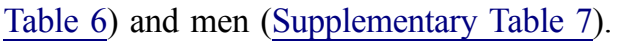

Considering that significant lung diseases might affect our findings, we further excluded participants who selfreported COPD and bronchiectasis at follow-up $(n=184)$. The excluded data were also included in the Poisson regression model and the Cox proportional hazards model for analysis. We found that the results were not affected after excluding patients' self-reported COPD and bronchiectasis in women (Supplementary Table 8) and men (Supplementary Table 9).

\section{Discussion}

This prospective, open cohort study was conducted in China using data from multiple health management centres. The results of the specific health examinations suggested that overweight and/or obesity was arisk factor for incident 
Table I Characteristics of 42,304 Participants Included in the Study

\begin{tabular}{|c|c|c|c|c|c|c|}
\hline \multirow[t]{2}{*}{ Characteristics } & \multicolumn{3}{|l|}{ Men $(26,009)$} & \multicolumn{3}{|c|}{ Women $(16,295)$} \\
\hline & $\begin{array}{l}\text { Asthma } \\
(n=52)\end{array}$ & $\begin{array}{l}\text { Control } \\
(n=25,957)\end{array}$ & Pvalue & $\begin{array}{l}\text { Asthma } \\
(n=38)\end{array}$ & $\begin{array}{l}\text { Control } \\
(n=16,257)\end{array}$ & Pvalue \\
\hline Age, years & $46.67(I I .43)$ & $42.25(12.57)$ & $0.00 *$ & $47.71(10.95)$ & $43.22(13.32)$ & $0.01 *$ \\
\hline $\mathrm{BMI}, \mathrm{kg} / \mathrm{m}^{2}$ & $25.49(3.48)$ & $25.78(3.5 I)$ & 0.55 & $23.77(3.24)$ & $23.47(3.57)$ & 0.55 \\
\hline SBP & $133.21(21.23)$ & $130.44(17.08)$ & 0.31 & $120.82(17.05)$ & $120.68(18.92)$ & 0.96 \\
\hline DBP & $83.94(10.13)$ & $81.29(12.32)$ & $0.04 *$ & $74.66(10.67)$ & $72.84(11.56)$ & 0.26 \\
\hline HDL-C & $52.12(13.14)$ & $49.69(11.25)$ & 0.13 & $57.27(11.95)$ & $56.57(11.79)$ & 0.71 \\
\hline TGs & $160.09(100.93)$ & $158.06(147.73)$ & 0.88 & $116.78(66.13)$ & $102.05(80.82)$ & $0.04 *$ \\
\hline FPG & $100.24(16.66)$ & $99.08(25.39)$ & 0.58 & $93.47(10.30)$ & $94.44(20.26)$ & 0.60 \\
\hline \multicolumn{7}{|l|}{ BMI } \\
\hline$<25 \mathrm{~kg} / \mathrm{m}^{2}$ & $26(50.00)$ & $10,760(4 \mid .45)$ & & I8(47.37) & $10,498(64.58)$ & \\
\hline$\geq 25 \mathrm{~kg} / \mathrm{m}^{2}$ & $26(50.00)$ & $15,197(58.55)$ & 0.21 & $20(52.63)$ & $5759(35.42)$ & $0.03^{*}$ \\
\hline \multicolumn{7}{|l|}{ HDL-C } \\
\hline$\geq 35 \mathrm{mg} / \mathrm{dl}(\mathrm{male}) / \geq 39 \mathrm{mg} / \mathrm{dl}(\mathrm{female})$ & $49(94.23)$ & $24,454(94.21)$ & & $36(94.94)$ & I5,534 (95.55) & \\
\hline$<35 \mathrm{mg} / \mathrm{dl}($ male) $) /<39 \mathrm{mg} / \mathrm{dl}($ female $)$ & $3(5.77)$ & $1503(5.79)$ & 1.00 & $2(5.26)$ & $723(4.55)$ & 0.81 \\
\hline \multicolumn{7}{|l|}{ TGs } \\
\hline$<150 \mathrm{mg} / \mathrm{dl}$ & $30(57.69)$ & $16,653(64.16)$ & & $28(73.68)$ & $13,760(84.64)$ & \\
\hline$\geq 150 \mathrm{mg} / \mathrm{dl}$ & $22(42.31)$ & $9340(35.98)$ & 0.33 & $10(26.32)$ & $2497(15.36)$ & 0.07 \\
\hline \multicolumn{7}{|l|}{ FPG } \\
\hline$<110 \mathrm{mg} / \mathrm{dl}$ & $4 \mathrm{I}(78.85)$ & $22,114(85.19)$ & & $36(94.94)$ & I5,534 (95.55) & \\
\hline$\geq 110 \mathrm{mg} / \mathrm{dl}$ & II (2I.I5) & $3843(14.81)$ & 0.20 & $2(5.26)$ & $723(4.55)$ & 0.38 \\
\hline \multicolumn{7}{|l|}{ BP } \\
\hline$<140 / 90 \mathrm{mmHg}$ & $32(61.54)$ & $17,587(67.75)$ & & $32(84.21)$ & $13,565(83.44)$ & \\
\hline$\geq 140 / 90 \mathrm{mmHg}$ & $20(38.46)$ & $8370(32.25)$ & 0.34 & $6(15.79)$ & $2692(16.56)$ & 0.90 \\
\hline History of hypertension & $7(13.46)$ & $2258(8.70)$ & 0.23 & $3(7.89)$ & $995(6.12)$ & 0.65 \\
\hline History of diabetes & I (I.92) & $830(3.20)$ & 0.61 & $0(0.00)$ & $395(100.00)$ & \\
\hline Metabolic Syndrome & $10(19.23)$ & $4830(18.61)$ & 0.91 & $2(5.26)$ & $1177(7.24)$ & 0.64 \\
\hline Drinking status & $22(42.31)$ & $668 \mid(25.74)$ & $0.01 *$ & $0(0.00)$ & $4 I(0.25)$ & I \\
\hline Smoking status & $19(36.54)$ & $5349(20.61)$ & $0.01 *$ & $0(0.00)$ & $0(0.00)$ & l \\
\hline \multicolumn{7}{|l|}{ Componentsofmetabolicsyndrome } \\
\hline Overweight or obesity & $26(50.00)$ & $15,197(58.55)$ & 0.21 & $20(52.63)$ & $5759(35.42)$ & $0.03^{*}$ \\
\hline Hyperglycemia & $12(23.08)$ & $3943(15.19)$ & 0.12 & $2(5.26)$ & $1609(9.90)$ & 0.35 \\
\hline Hypertension & $20(38.46)$ & $8832(34.03)$ & 0.50 & $7(18.42)$ & $2963(18.23)$ & 0.98 \\
\hline Dyslipidemia & $22(42.31)$ & $9783(37.69)$ & 0.49 & II (28.95) & $2837(17.45)$ & 0.07 \\
\hline \multicolumn{7}{|l|}{ Respiratory diseases } \\
\hline Rhinitis & $\mathrm{I}(1.92)$ & $97(0.37)$ & 0.10 & $0(0.00)$ & $28(0.00)$ & I \\
\hline Nasal polyps & $\mathrm{I}(1.92)$ & $4 \mid(0.16)$ & $0.01 *$ & $0(0.00)$ & $\mathrm{II}(0.00)$ & 1 \\
\hline Pulmonary infection & I (1.92) & $119(0.46)$ & 0.15 & $2(5.26)$ & $82(0.50)$ & $0.00 *$ \\
\hline Pneumonia & $7(13.46)$ & $308(1.19)$ & $0.00 *$ & $7(18.42)$ & $198(0.01)$ & $0.00 *$ \\
\hline Bronchitis & $8(15.38)$ & $313(1.21)$ & $0.00 *$ & $10(26.32)$ & $236(0.02)$ & $0.00 *$ \\
\hline COPD & $7(13.46)$ & $95(0.37)$ & $0.00 *$ & $3(7.89)$ & $23(0.00)$ & $0.00 *$ \\
\hline Bronchiectasis & $\mathrm{I}(1.92)$ & $39(0.15)$ & $0.01 *$ & $\mathrm{I}(2.63)$ & $23(0.001)$ & $0.00 *$ \\
\hline
\end{tabular}

Note: ${ }^{*} \mathrm{P}<0.05$.

Abbreviations: BMI, body mass index; SBP, systolic blood pressure; DBP, diastolic blood pressure; BP, blood pressure; HDL-C, high-density lipoprotein cholesterol; TGs, triglycerides; FPG, fasting plasma glucose; COPD, chronic obstructive pulmonary disease; IRR, incident rate ratios.

asthma among only women, not men. However, there was no significant correlation between metabolic syndrome and incident asthma in either men or women. These findings, based on alongitudinal analysis of alarge adult population data set, confirm the importance of overweight and/or obesity as arisk factor for incident asthma in adult women. 
Table 2 Longitudinal Associations Between the Metabolic Syndrome and Incident Asthma

\begin{tabular}{|l|l|l|l|l|}
\hline \multirow{2}{*}{ Statistical Models } & \multicolumn{2}{l|}{ Men } & \multicolumn{2}{l|}{ Women } \\
\cline { 2 - 4 } & HR (95\% CI) & & HR (95\% CI) \\
\hline Mode I & & 0.56 & \\
Metabolic syndrome+ & $0.81(0.40-1.63)$ & 0.81 & $0.45(0.10-1.95)$ \\
Metabolic syndrome- & $0.92(0.46-1.83)$ & & $0.82(0.20-3.40)$ \\
\hline Model 2 & & 0.66 & \\
Hypertension+ & $0.87(0.48-1.60)$ & 0.84 & $0.55(0.22-1.35)$ \\
Dyslipidemia+ & $1.06(0.59-1.90)$ & 0.31 & $1.23(0.58-2.58)$ \\
Hyperglycemia+ & $1.42(0.73-2.79)$ & 0.37 & $0.37(0.09-1.61)$ \\
Overweight and/or obesity+ & $0.77(0.43-1.37)$ & 0.92 & $2.94(1.47-5.89)$ \\
Hypertension- & $1.03(0.57-1.85)$ & $0.76(0.32-1.80)$ \\
Dyslipidemia- & $1.04(0.58-1.86)$ & 0.90 & $1.36(0.65-2.86)$ \\
Hyperglycemia- & $1.70(0.87-3.30)$ & 0.12 & 0.12 \\
Overweight and/or obesity- & $0.76(0.42-1.35)$ & 0.35 & 0.19 \\
\hline
\end{tabular}

Notes: +Adjusted age, smoking and drinking status; -unadjusted age, smoking and drinking status. * $\mathrm{P}<0.05$.

Abbreviations: HR, hazard ratio; IRR, incident rate ratios.

Table 3 Longitudinal Associations Between Overweight and/or Obesity and Incident Asthma

\begin{tabular}{|c|l|l|l|l|}
\hline \multirow{2}{*}{$\begin{array}{l}\text { Statistical } \\
\text { Models }\end{array}$} & \multicolumn{2}{|l|}{ Men } & \multicolumn{2}{l|}{ Women } \\
\cline { 2 - 5 } & HR (95\% & $P$ & HR (95\% CI) & $P$ \\
\hline $\begin{array}{c}\text { BMI- } \\
<25 \mathrm{~kg} / \mathrm{m}^{2} \\
\geq 25 \mathrm{~kg} / \mathrm{m}^{2}\end{array}$ & $\begin{array}{l}\text { I.6I(0.33- } \\
7.74)\end{array}$ & 0.56 & $\begin{array}{l}6.86(1.84- \\
25.58)\end{array}$ & $0.00^{*}$ \\
\hline $\begin{array}{c}\mathrm{BMI}+ \\
<25 \mathrm{~kg} / \mathrm{m}^{2} \\
\geq 25 \mathrm{~kg} / \mathrm{m}^{2}\end{array}$ & $\begin{array}{l}0.96(0.18- \\
5.15)\end{array}$ & 0.97 & $\begin{array}{l}5.05(1.26- \\
20.22)\end{array}$ & $0.02^{*}$ \\
\hline
\end{tabular}

Notes: +Adjusted age, smoking and drinking status; -unadjusted age, smoking and drinking status. $* P<0.05$.

Abbreviations: HR, hazard ratio; IRR, incident rate ratios; BMI, body mass index.

In recent years, findings on metabolic syndrome and asthma have been inconsistent. Studies in the US, Norway, and South Korea have shown that metabolic syndrome is associated with incident asthma. ${ }^{20,22,23}$ However, among these studies, the large retrospective cohort study from Norway showed that high WC (adjusted OR 1.62, 95\% CI 1.36-1.94) and elevated glucose or diabetes (adjusted OR $1.43,95 \%$ CI 1.01-2.04) were associated with an increased risk of incident asthma in adults. In addition, acohort followed for over 25 years in the USA reported that after adjusting for BMI, the correlation between metabolic syndrome and asthma attacks was no longer statistically significant among women $(P=0.44)$. Interestingly, aretrospective cohort study in Japan showed that obesity, not metabolic syndrome, was asignificant risk factor for the incidence of late-onset asthma but only in middle-aged Japanese women, ${ }^{21}$ which was similar to the result of our open cohort study. Our observations suggest that overweight and/or obesity, not metabolic syndrome, is asignificant risk factor for incident asthma, but only in Chinese women, not in men. The inconsistency between the findings of previous studies and our current study may be due to the differences in study designs, populations and diagnostic criteria for metabolic syndrome.

Table 4 Longitudinal Associations Between BMI and Incident Asthma

\begin{tabular}{|l|l|l|l|l|}
\hline \multirow{2}{*}{ Variables } & \multicolumn{2}{|l|}{ Men } & Women \\
\cline { 2 - 5 } & HR (95\% Cl) & $P$ & HR (95\% Cl) & $P$ \\
\hline BMI $25.0-29.9 \mathrm{~kg} / \mathrm{m}^{2}-$ & $0.813(0.46 \mathrm{I}-1.435)$ & 0.48 & $3.194(1.593-6.404)$ & $0.00 I^{*}$ \\
$\mathrm{BMI} \geq 30 \mathrm{~kg} / \mathrm{m}^{2}-$ & $0.783(0.276-2.275)$ & 0.67 & $8.134(3.126-21.168)$ & $0.000^{*}$ \\
$\mathrm{BMI} 25.0-29.9 \mathrm{~kg} / \mathrm{m}^{2}+$ & $0.784(0.443-1.387)$ & 0.40 & $2.711(1.310-5.610)$ & $0.007^{*}$ \\
$\mathrm{BMI} \geq 30 \mathrm{~kg} / \mathrm{m}^{2}+$ & $0.769(0.268-2.21 \mathrm{I})$ & 0.63 & $6.405(2.339-17.54 \mathrm{I})$ & $0.000^{*}$ \\
\hline
\end{tabular}

Notes: +Adjusted age, smoking and drinking status; -unadjusted age, smoking and drinking status. $* P<0.05$.

Abbreviations: HR, hazard ratio; IRR, incident rate ratios; BMI, body mass index. 
We need to carefully interpret the results for the components, as these components in the definition of metabolic syndrome are dichotomous and do not allow for adjustment. ${ }^{13}$ In our study, TGs were statistically significant in univariate analysis among women $(P=0.037)$. However, the association was no longer statistically significant after adjustment for covariates $(P>0.050)$. Further studies should address the individual component in more detail; for example, repeated measurements of consecutive serum levels in acohort study should be performed to eliminate confounding factors and help identify the associations of the components of metabolic syndrome with asthma.

There are several possible mechanisms connecting overweight and/or obesity and incident asthma. We observed that obesity may change pulmonary physiology and lung function in adults. ${ }^{28,29}$ Excessive accumulation of fat in the chest and abdomen might cause compression of the lungs, accompanied by reduced lung volume. In fact, we have shown that obesity increased the folding of the surrounding airways and parenchyma, especially in asthmatic patients with late-onset disease. ${ }^{30}$ In addition, adipocytokines (leptin and resistin) produced by adipose tissue have been suggested to promote systemic inflammation, which may induce asthma. ${ }^{31,32}$ Patients with $\mathrm{aBMI} \geq 25 \mathrm{~kg} / \mathrm{m}^{2}$ showed higher levels of leptin, and this cytokine difference was also found in female patients with asthma $(\mathrm{P}<0.05) .{ }^{33}$ On the other hand, asthma and obesity have considerable genetic components. The obesityasthma association may also be due to common genes shared by both obesity and asthma. Candidate gene studies have reported afew genes associated with asthma and obesity, such as PRKCA and NR3C1. ${ }^{34,35}$ The specific mechanism of the relationship between overweight and/ or obesity and asthma still needs more research to explore.

There were some limitations to our study. First, this study lacks demographic characteristics such as birthplace, residence, occupation, marriage, income, etc. This may be due to the incomplete basic information filled out by the research subjects in various medical examination centers, which may have acertain impact on the results. Second, the measurement of various indicators of metabolic syndrome over time was not included, as some study subjects did not participate in regular physical examinations. Third, the doctor diagnosed asthma based on the patient 's lung function indicators and clinical manifestations, but we did not collect data on the lung function indicators, which may affect the research results to acertain extent. Fourth, metabolic syndrome was diagnosed using the diagnostic criteria recommended by the CDS in 2004; however, it did not include WC, which may not reflect overweight and/or obesity, as many studies have shown that WC was closely related to asthma. ${ }^{36-38}$ Therefore, we hope that the diagnostic criteria for metabolic syndrome will be updated in China.

In conclusion, the study confirmed overweight and/or obesity as arisk factor for incident asthma only among women, not men. However, our study suggested that metabolic syndrome was not significantly associated with incident asthma in both women and men. The findings of this study warrant further research, particularly addressing the associations between the components of metabolic syndrome and incident asthma in prospective studies.

\section{Abbreviations}

$\mathrm{HR}$, hazard ratio; IRR, incident rate ratios; CI, confidence interval; WHO, World Health Organization; SBP, systolic blood pressure; DBP, diastolic blood pressure; FPG, fasting plasma glucose; TGs, triglycerides; HDL-C, high-density lipoprotein cholesterol; IR, insulin resistance; CDS, Chinese Medical Association Diabetes Division; BMI, body mass index; COPD, chronic obstructive pulmonary disease; WC, waist circumference.

\section{Funding}

This work was supported by the National Natural Science Foundation of China (Grant 81400072), the Natural Science Foundation of Shandong Province (Grant 2013HQ047), the Medicine and health development plan of Shandong Province (Grant 2017WS113), the humanities and social sciences youth team project of Shandong University (Grant IFYT18036). The funding bodies were not involved in the design of the study, the collection, analysis, and interpretation of data and the preparation of the manuscript.

\section{Disclosure}

The authors declare that they have no known competing financial interests or personal relationships that could have appeared to influence the work reported in this paper. The authors report no conflicts of interest in this work. 


\section{References}

1. Mims JW. Asthma: definitions and pathophysiology. Int Forum Allergy RH. 2015;5(Suppl 1):S2-S6.

2. Moraes TJ, Sears MR, Subbarao P. Epidemiology of asthma and influence of ethnicity. Semin Respir Crit Care Med. 2018;39(1):311. doi:10.1055/s-0037-1618568

3. Aaron SD, Boulet LP, Reddel HK, Gershon AS. Underdiagnosis and overdiagnosis of asthma. Am JRespir Crit Care . 2018;198(8):10121020. doi:10.1164/rccm.201804-0682CI

4. Collaborators GCRD. Global, regional, and national deaths, prevalence, disability-adjusted life years, and years lived with disability for chronic obstructive pulmonary disease and asthma, 1990-2015: asystematic analysis for the global burden of disease study 2015. Lancet Respir Med. 2017;5(9):691-706.

5. Organization WH. Chronic Respiratory Diseases: Scope: Asthma. Vol. 2020; 2020:235

6. GINA. Main Report - Global Initiative for Asthma - GINA. Vol. 2020; 2019:2019

7. Beasley R, Semprini A, Mitchell EA. Risk factors for asthma: is prevention possible? Lancet (London). 2015;386(9998):1075-1085. doi:10.1016/S0140-6736(15)00156-7

8. Ilmarinen P, Tuomisto LE, Kankaanranta H. Phenotypes, risk factors, and mechanisms of adult-onset asthma. Mediat Inflamm. 2015;2015:514868. doi: $10.1155 / 2015 / 514868$

9. Lin J, Wang W, Chen P, et al. Prevalence and risk factors of asthma in mainland China: the CARE study. Respir Med. 2018;137:48-54. doi:10.1016/j.rmed.2018.02.010

10. Lieberoth S, Backer V, Kyvik K, et al. Intake of alcohol and risk of adult-onset asthma. Respir Med. 2012;106(2):184-188. doi:10.1016/j. rmed.2011.11.004

11. Peters U, Dixon AE, Forno E. Obesity and asthma. J Allergy Clin Immuno. 2018;141(4):1169-1179. doi:10.1016/j.jaci.2018 .02 .004

12. Ciprandi G, Schiavetti I, Fontana R, Sorbello V, Ricciardolo F. Overweight and obesity as risk factors for impaired lung function in patients with asthma: a real-life experience. Allergy Asthma Proc. 2014;35(4):E62-E71. doi:10.2500/aap.2014.35.3773

13. Alberti KGMM, Eckel RH, Grundy SM, et al. Harmonizing the metabolic syndrome: ajoint interim statement of theInternational diabetes federation task force on epidemiology and prevention; national heart, lung, and blood institute; American heart association; world heart federation; international atherosclerosis society; and international association for the study of obesity. Circulation. 2009;120:1640-1645.

14. Sookoian S, Pirola CJ. Metabolic syndrome: from the genetics to the pathophysiology. Curr Hypertens Rep. 2011;13(2):149-157. doi:10.1007/s11906-010-0164-9

15. Samson SL, Garber AJ. Metabolic syndrome. Endocrinol Metab Clin. 2014;43(1):1-23. doi:10.1016/j.ecl.2013.09.009

16. Ali Z, Ulrik CS, Agner T, Thomsen SF. Association between atopic dermatitis and the metabolic syndrome: asystematic review . Dermatology (Basel). 2018;234(3-4):79-85. doi:10.1159/ 000491593

17. Baffi CW, Wood L, Winnica D, et al. Metabolic syndrome and the lung. Chest. 2016;149(6):1525-1534. doi:10.1016/j.chest.2015.12.034

18. Leone N, Courbon D, Thomas F, et al. Lung function impairment and metabolic syndrome: the critical role of abdominal obesity. $\mathrm{Am} \mathrm{J}$ Respir Crit Care . 2009;179(6):509-516. doi:10.1164/rccm.200807$1195 \mathrm{OC}$
19. Forno E, Han Y, Mullen J, Celedon JC. Overweight, obesity, and lung function in children and adults-a meta-analysis. J Allergy Clin Immunol . 2018;6(2):570-581.

20. Assad N, Qualls C, Smith LJ, et al. Body mass index is astronger predictor than the metabolic syndrome for future asthma in women. The longitudinal CARDIA study . Am J Respir Crit Care Med . 2013;188:319-326. doi:10.1164/rccm.201303-0457OC

21. Tomita Y, Fukutomi Y, Irie M, et al. Obesity, but not metabolic syndrome, as arisk factor for late-onset asthma in Japanese women . Allergol Int. 2019;68(2):240-246. doi:10.1016/j.alit.2018.10.003

22. Park S, Choi N, Kim S, Lee C. The relationship between metabolic syndrome and asthma in the elderly. Sci Rep. 2018;8(1):9378.

23. Brumpton BM, Camargo CAJ, Romundstad PR, Langhammer A, Chen Y, Mai X. Metabolic syndrome and incidence of asthma in adults: the HUNT study. Eur Respir J. 2013;42(6):1495-1502. doi:10.1183/09031936.00046013

24. Liu Y, Xing P, Xu X, et al. Shandong multi-center health management longitudinal cohort. JShandong Univ . 2017;55(06):30-36.

25. Fokkens W, Lund V, Mullol J, et al. European position paper on rhinosinusitis and nasal polyps 2012. Rhinology. 2012;50(1):1-298. doi:10.4193/Rhino50E2

26. Asthma Section RDBC. Guidelines for the prevention and treatment of bronchial asthma (definition, diagnosis, treatment, education and management of bronchial asthma). Chin JIntMed . 2003;(11):68-73.

27. Group CMAD. Recommendations of the Chinese medical association diabetes division on metabolic syndrome. Clin JDiabetes . 2004; (03):5-10.

28. Watson RA, Pride NB, Thomas EL, et al. Reduction of total lung capacity in obese men: comparison of total intrathoracic and gas volumes. JAppl Physiol . 2010;108(6):1605-1612. doi:10.1152/japplphysiol.01267.2009

29. Dixon AE, Peters U. The effect of obesity on lung function. Expert Rev Respir Med. 2018;12(9):755-767. doi:10.1080/17476348.2018.1506331

30. Al-Alwan A, Bates JHT, Chapman DG, Kaminsky DA, DeSarno MJ, Irvin CG. The nonallergic asthma of obesity. Amatter of distal lung compliance . Am JRespir Crit Care . 2014;189(12):1494-1502. doi:10.1164/rcem.201401-0178OC

31. Sood A, Shore SA. Adiponectin, leptin, and resistin in asthma: basic mechanisms through population studies. $J$ Allergy (Cairo) . 2013;2013:785835. doi:10.1155/2013/785835

32. Kattan M, Kumar R, Bloomberg GR, et al. Asthma control, adiposity, and adipokines among inner-city adolescents. J Allergy Clin Immunol . 2010;125(3):584-592. doi:10.1016/j.jaci.2010.01.053

33. Muc M, Todo-Bom A, Mota-Pinto A, Vale-Pereira S, Loureiro C. Leptin and resistin in overweight patients with and without asthma. Allergol Immunopath. 2014;42(5):415-421. doi:10.1016/j.aller.2013.03.004

34. Murphy A, Tantisira KG, Soto-Quiros ME, et al. Apositional candidate gene for body mass index and asthma. Am J Hum Genet . 2009;85(1):87-96. doi:10.1016/j.ajhg.2009.06.011

35. Beuther DA, Weiss ST, Sutherland ER. Obesity and asthma. Am JRespir Crit Care . 2006;174(2):112-119. doi:10.1164/rccm.200602-231PP

36. Kronander U, Falkenberg M, Zetterström O. Prevalence and incidence of asthma related to waist circumference and BMI in aSwedish community sample . Respir Med. 2004;98(11):1108-1116. doi:10.1016/j.rmed.2004.03.022

37. Jeong A, Imboden M, Hansen S, et al. Heterogeneity of obesityasthma association disentangled by latent class analysis, the SAPALDIA cohort. Respir Med. 2017;125:25-32. doi:10.1016/j. rmed.2017.02.014

38. Vangeepuram N, Teitelbaum SL, Galvez MP, Brenner B, Doucette J. Measures of obesity associated with asthma diagnosis in ethnic minority children. JObes. 2011;2011. 


\section{Publish your work in this journal}

Diabetes, Metabolic Syndrome and Obesity: Targets and Therapy is an international, peer-reviewed open-access journal committed to the rapid publication of the latest laboratory and clinical findings in the fields of diabetes, metabolic syndrome and obesity research. Original research, review, case reports, hypothesis formation, expert opinion and commentaries are all considered for publication. The manuscript management system is completely online and includes a very quick and fair peer-review system, which is all easy to use. Visit http://www.dovepress.com/testimonials.php to read real quotes from published authors. 